\title{
ALFABETIZACIÓN CIENTÍFICA: PENSAMIENTO Y PRÁCTICAS DE ENSEÑANZA DEL PROFESORADO DE FÍSICA EN EL BACHILLERATO DE EDUCACIÓN SECUNDARIA EN URUGUAY
}

\author{
Scientific literacy: thinking and teaching practices of \\ Physics teachers in the Baccalaureate of Secondary \\ Education in Uruguay
}

María Cristina Araújo Avelino

Liceo N² Prof. Miguel Banchero Noaín, Consejo Enseñanza Secundaria

(Carmelo- Uruguay)

caraujo45@gmail.com

Marcela Ballesta Wolmark

Instituto de Profesores Artigas, Consejo de Formación en Educación, Liceo No10 Carlos Vaz Ferreira, Consejo Enseñanza Secundaria

(Montevideo-Uruguay)

mballestaw@gmail.com

\section{Resumen:}

Recibido 31 de mayo de 2019 Aprobado 19 de julio de 2019

El presente trabajo recoge insumos procedentes de dos investigaciones educativas recientes, que tomaron como objeto de estudio las concepciones del profesorado de Física de Uruguay sobre diversos aspectos de la enseñanza de Física en el nivel medio superior de la educación formal y las acciones que desarrollan, tomando particularmente como eje articulador la Alfabetización Científica. Opiniones sobre finalidades educativas, intencionalidades curriculares, prácticas docentes, así como la explicitación de estrategias y actividades didácticas seleccionadas y reflexiones sobre las políticas educativas, fueron relevados a través de un cuestionario semiestructurado en línea, aplicado a una muestra representativa de docentes. Se describen aspectos del recorte empírico y del enfoque metodológico, así como los principales hallazgos. Se evidencian tensiones con relación a la dimensión de alfabetización científica y prácticas de enseñanza en las aulas e instituciones educativas al tiempo que se manifiestan algunas contradicciones entre los discursos y las acciones que desarrolla el profesorado.

Palabras clave: concepciones docentes, finalidades educativas, alfabetización científica, currículo, didáctica de las ciencias, prácticas de enseñanza.

\begin{abstract}
:
This study collets data deriving from two recent educational researches focused on the study of the conceptions held by the body of teachers of Physics in Uruguay about various aspects of the teaching of Physics in high school in formal education, and the actions taken considering scientific literacy. In order to do that, opinions about educational aims, curricular intentions and teaching practices, as well as explicitation of selected strategies, didactic activities and reflection on the educational strategies were collected through a semi-structured online questionnaire on a representative sample of teachers. Aspects of the empirical section and the methodological focus as well as the mains findings are described.

Tension in connection with the dimension of scientific literacy and teaching practices in the classroom become evident, and there is some contradiction between what is verbalized and the actual teachers' actions.
\end{abstract}

Key words: teachers' conceptions, educational aims, scientific literacy, curriculum, teaching of the sciences, teaching practices. 


\section{Introducción}

En este artículo, se presentan de modo sintético algunas elaboraciones conceptuales y reflexiones realizadas por las autoras a partir de las investigaciones llevadas a cabo para obtener el grado de Maestría en Educación, Sociedad y Política (Facultad Latinoamericana de Ciencias Sociales) (Araújo, 2018; Ballesta, 2018). Dichas investigaciones, se sustentan sobre algunos pilares estructurantes: concepciones del profesorado de Física, currículo e intencionalidades curriculares, finalidades educativas, práctica docente, transposición didáctica y políticas educativas. Particularmente, este artículo presenta los resultados de la aplicación de uno de los instrumentos de indagación, un cuestionario en línea, que se implementa en la etapa inicial del trabajo de campo de cada investigación, con el objetivo de conocer el pensamiento y las acciones desarrolladas por el profesorado de Física en relación a las finalidades educativas e intencionalidades curriculares que sustentan sus prácticas docentes, con especial atención en lo que respecta a la alfabetización científica, en el marco del nivel medio superior de Educación Secundaria en el Uruguay.

Se entiende que, recoger, sistematizar y elaborar reflexivamente respecto a diversos aspectos que se relacionan con las concepciones y las prácticas de enseñanza de los docentes de Física de Enseñanza Media en Uruguay puede resultar un aporte significativo para la comunidad educativa, política y la sociedad en general, en tanto hasta el momento no se conocen estudios científicos, nacionales, en esta área y recorte empírico. Sin embargo, en la búsqueda de antecedentes, se logra identificar algunos trabajos de investigación de los que se toma aportes, en el entendido de que comparten algunos elementos comunes y permiten observar desde un lugar de mayor significatividad. Es así como se atiende a la producción de Revetria (2014), que investiga sobre las concepciones de alfabetización científica en profesores de Ciencias Naturales en Uruguay y de Valdivia (2016), en Chile, que considera la alfabetización científica y su apropiación por parte de los docentes con relación a las demandas curriculares de reformas educativas implementadas en ese país.

A continuación, se desarrolla brevemente aspectos del marco teórico para dar encuadre a los problemas y a los hallazgos (parciales) de las investigaciones llevadas a cabo por las autoras y sintetizadas en este documento.

\section{Marco teórico}

En Uruguay, así como en muchos otros países, hoy se debate intensamente, procurando establecer las finalidades educativas de los distintos trayectos de formación, que la sociedad del siglo XXI requiere para la promoción de ciudadanas y ciudadanos cultos, participativos y críticos, siendo una preocupación ampliamente compartida, principalmente por el sistema político, el colectivo docente, las familias, así como por organismos internacionales.

Particularmente respecto a la educación científica, Lemke (2006), se pregunta cuáles son las contribuciones más importantes que ésta puede hacer al estudiantado y a la sociedad en su conjunto, que sirva a los intereses de toda la gente. Inicialmente dice, hay que pensar en cómo crear una nueva cultura científica a la que los alumnos, en su mayoría, no rechacen. Criticando y poniendo rápidamente en evidencia uno de los asuntos a los que debe dirigir sus esfuerzos la 
actual investigación didáctica de las ciencias. A su vez expresa: "Necesitamos prestar más atención al aprendizaje que dure toda la vida, al aprendizaje que desmitifique el razonamiento cuantitativo, al aprendizaje que provea de pistas para pensar con múltiples representaciones en nuestro nuevo mundo multimedial" (Lemke, 2006, p. 6). En concordancia con lo que Pozo et al (2006) llaman, la nueva cultura del aprendizaje, caracterizada por estar frente a la sociedad de la información, del conocimiento múltiple e incierto y del aprendizaje continuo.

En consideración de lo anterior, la actual investigación en el campo de la didáctica de las ciencias, así como las construcciones y reflexiones de expertos en el área, han acordado en general que, el modelo contextualizado de alfabetización científica es el que mejor interpreta los propósitos de la enseñanza de las ciencias (Acevedo, 2004).

Así, Gil, Sifredo, Valdés y Vilches (2005) entienden que:

Las propuestas actuales a favor de una alfabetización científica para todos los ciudadanos y ciudadanas van más allá de la tradicional importancia concedida - más verbal que real - a la educación científica y tecnológica, para hacer posible el desarrollo futuro. Esa educación científica se ha convertido, en opinión de los expertos, en una exigencia urgente, en un factor esencial del desarrollo de las personas y de los pueblos, también a corto plazo. (Gil Pérez et. al, 2005, p. 16)

Desde organismos internacionales, a modo de referencia, en la Conferencia Mundial sobre la Ciencia para el siglo XXI: Un nuevo compromiso, se sostiene que:

34. La enseñanza científica, en sentido amplio, sin discriminación y que abarque todos los niveles y modalidades es un requisito previo esencial de la democracia y el desarrollo sostenible.[...] Hoy más que nunca es necesario fomentar y difundir la alfabetización científica en todas las culturas y todos los sectores de la sociedad así como las capacidades de razonamiento y las competencias prácticas y una apreciación de los principios éticos, a fin de mejorar la participación de los ciudadanos en la adopción de decisiones relativas a la aplicación de los nuevos conocimientos. (UNESCO, 1999, p. 5-6)

Los países participantes, al acompañar las declaraciones realizan un nuevo compromiso con la ciencia en las sociedades del siglo XXI. Es así, que la alfabetización científica está hoy sólidamente instalada en el campo de la enseñanza de las ciencias y en las agendas políticas de los países, así como de organismos internacionales. La investigación didáctica ha procurado elaborar conocimiento para orientar no sólo las prácticas docentes, sino también la producción de materiales didácticos, la elaboración del currículo, la formación docente, así como investigaciones en el orden del aprendizaje de las ciencias, entre otros, favoreciendo de este modo la comprensión y elaboración conceptual en la coyuntura alfabetizadora.

A nivel nacional, en este marco sociopolítico educativo, la alfabetización científica se ha incorporado, al menos como enunciado, en documentos programáticos de diferentes asignaturas correspondientes a distintos niveles del sistema de educación formal, como ser, $3^{\circ}$ Ciclo Básico Química, $1^{\circ}$ Bachillerato: Física, Ciencias Biológicas, Química y Astronomía, $2^{\circ}$ Bachillerato: Ciencias Biológicas y Química, $3^{\circ}$ Bachillerato: Ciencias Biológicas y Química. Existiendo además otros documentos programáticos que, sin mencionar a la alfabetización científica, refieren a ella de modo implícito; estos son: Fisicoquímica del Plan 2008 para for- 
mación de maestros y el Programa de Educación Inicial y Primaria (2008). En la órbita de las políticas educativas nacionales, y desde los diagnósticos y orientaciones elaboradas por parte de las Inspecciones técnicas de las asignaturas científicas (Física, Química, Biología y Astronomía) de la enseñanza media, se reconoce que los docentes y una buena enseñanza son aspectos clave. En este marco, Luaces (2014), en documento publicado por la Administración Nacional de Educación Pública (ANEP), expresa que actualmente muchos estudiantes no están alfabetizados científicamente como consecuencia de problemáticas reconocidas que enfrenta la educación en ciencias. Así conecta asuntos como la pérdida progresiva de motivación de los estudiantes a medida que avanza su escolaridad en ciencias con la forma en que son presentados los problemas en la enseñanza de las ciencias, alejados de lo cotidiano, enfatizando en contenidos abstractos, poco atractivos o sin correlatos empíricos y por otro lado, el acento puesto especialmente en una finalidad propedéutica y la presentación de una ciencia academicista, clásica, del siglo XIX, que no siempre aborda la ciencia y tecnología contemporáneas. Como consecuencias asociadas a estas problemáticas, muchos estudiantes: no están alfabetizados científicamente, es decir, no están en condiciones de tomar decisiones tecnocientíficas y desempeñarse como ciudadanos de manera adecuada; no aprenden conocimiento científico ni alcanzan una comprensión adecuada de la Naturaleza de la Ciencia y tampoco logran valorar componentes sociales, afectivos y culturales involucrados en el aprendizaje de las ciencias. Afilia al enfoque ciencia-tecnología-sociedad-medioambiente para lograr la alfabetización científica y para articular con las necesidades e intereses de las personas

Plantea Meinardi (2010), en esta coyuntura, no es posible preservar la cultura científica a una élite. Conocer, manejar y valorar (Martín y Osorio, 2003), conforman un círculo virtuoso en relación con el desarrollo de la ciencia y la tecnología en el presente, y configuran finalidades para la cultura científica de todas y todos en el nuevo contrato social. Como se señaló anteriormente, se percibe la necesidad de desarrollar una ciudadanía científicamente culta. Qué se enseña, cuáles son los conocimientos que los estudiantes deben aprender, cómo se enseña y cómo se evalúa, son aspectos fundamentales sobre los cuales reflexionar, elaborar conceptualmente y, especialmente explicitar y comunicar a las comunidades educativas. El tratamiento de estos núcleos de interés en el área de la enseñanza de la Física en el nivel educativo medio en Uruguay, como en otras áreas de conocimiento, se produce en un campo de tensiones múltiples entre los diversos actores involucrados.

\subsection{Finalidades de enseñanza y orientaciones para la práctica docente}

Desde sus elaboraciones conceptuales para establecer finalidades de enseñanza de la ciencia escolar, Acevedo (2004) ubica el punto de partida para la reflexión en la relevancia de esta: ¿para quién es relevante?, ¿quién decide lo que es relevante en la ciencia escolar? Considerando que la alfabetización científica, no implica limitarse a una sola finalidad. Lo que sí subraya, es que la extensión de la alfabetización científica para toda la ciudadanía es incompatible con una finalidad exclusivamente propedéutica de la enseñanza. Por su parte Vildósola (2009) acompaña esta puntualización y, dado que entiende la ciencia como un producto 
cultural de la sociedad, sostiene que la enseñanza de las ciencias en concordancia con esto debe tener un fuerte énfasis social y humanista, promoviendo en el estudiantado una mejor comprensión de su naturaleza y de sus interacciones con la sociedad y la tecnología. En esta misma línea, Sasseron (2011) plantea la necesidad que se prepare a los estudiantes para un futuro sustentable, donde cada uno sea capaz de percibir que sus acciones individuales pueden repercutir en el colectivo social y en el medio ambiente y que deben asumir, por tanto, un activo y participativo papel en la toma de decisiones que afecten al conjunto.

Desde la investigación didáctica, Furió, Vilches, Guisasola, Romo (2001), Banet $(2007,2010)$, resaltan la importancia de conocer las diferencias entre lo que piensan los profesores y lo que se proponen desde la didáctica de las ciencias y las demandas de reforma curricular o educativa con el fin de evitar que el pensamiento del profesor se convierta en un obstáculo frente al cambio. Concluyen que el profesorado mantiene una concepción mayormente propedéutica respecto a la finalidad de la enseñanza de las ciencias. Así, la enseñanza de las ciencias se ocupa primordialmente de los contenidos de carácter conceptual; tendencia que se acentúa significativamente en el Bachillerato y presta escasa atención a otras dimensiones formativas (habilidades y destrezas de la investigación científica, Naturaleza de la Ciencia, relaciones Ciencia-Tecnología-Sociedad y actitudes, valores y normas de comportamiento). Se considera que una posible causa de este pensamiento del profesor recae en su formación docente. Formación inicial básicamente con dos características: 1) de tipo academicista, que lo lleva a considerar como adecuada una transmisión de conocimientos científicos conceptuales (leyes, teorías, etc.), más dirigida a la memorización que a la interpretación y comprensión de los fenómenos; que no los hace competentes en ámbitos de interés actual, como relaciones CTS o $\mathrm{NdC}, \mathrm{y}, 2)$ es deficiente en preparación didáctica. Estos hallazgos advierten y ponen en evidencias asuntos de interés para quienes investigan.

Considerando las orientaciones didácticas para la enseñanza de las ciencias en clave alfabetizadora, existe consenso en que la misma debe ser conducida atendiendo fundamentalmente a la contextualización, mediante la resolución de problemas auténticos, en procesos de investigación dirigida por el profesor o la profesora. Sasseron (2011) entiende que, al momento de planificar e instrumentar actividades que promuevan la alfabetización científica de los estudiantes se deben considerar necesariamente los Ejes Estructurantes de la Alfabetización Científica, que de acuerdo con su síntesis son tres. El primero, refiere a la comprensión básica de términos, conocimientos y conceptos científicos fundamentales. El segundo, corresponde a la comprensión de la naturaleza de las ciencias y de los factores éticos y políticos que circundan su práctica. Y, el tercero, comprende el entendimiento de las relaciones existentes entre Ciencia, tecnología, sociedad y medio ambiente. Por su parte, Sanmartí y Márquez (2012) plantean que, hoy en día, aprender a plantear preguntas investigables científicamente debería ser uno de los objetivos de la clase de ciencias. En este sentido, el contrato didáctico tradicional entre profesores y estudiantes, donde los primeros preguntan y los segundos responden, debe modificarse. El docente debe promover situaciones que provoquen al estudiante a formular preguntas a partir de las cuales pueda, para un fenómeno, describir, explicar, comprobar, generalizar, predecir y evaluar. 
En este escenario, se entiende entonces relevante, atender al profesorado en al menos dos aspectos: sus concepciones y sus prácticas de enseñanza. Tal como expresa Tobin (1988) citado en Vildósola (2009): “A pesar de los avances en la aceptación de los planteamientos de la alfabetización científica, en esta década aún persiste la duda sobre el grado de participación del profesorado para producir los cambios requeridos en la práctica de aula" (p. 75). La autora también plantea que:

Las actitudes, ideas o concepciones sobre la ciencia se han caracterizado por tener una expresión inconsciente e implícita, y las tendencias actuales abogan justamente, por promover una mejor comprensión y su explicitación. Se sabe que los procesos educativos están influidos por múltiples variables, pero cada vez hay un mayor acuerdo y reconocimiento en que lo que piensa el profesor de ciencias sobre la ciencia tiene un impacto cada vez mayor en el éxito de los estudiantes y de la propia enseñanza de las ciencias. (Vildósola, 2009, p. 151)

De aquí la necesidad de hacerlas emergen para su análisis en contexto.

\subsection{Concepciones docentes y lo curricular}

Desde el marco teórico considerado en las investigaciones llevadas a cabo por las autoras, las concepciones docentes se definen como un "entramado intelectual” (Díaz, Martínez, Roa y Sanhueza, 2010), es decir, un conjunto de teorías, pensamientos, creencias, representaciones que se originan y se desarrollan en la experiencia y están determinadas por los contextos educativos. Tienen carácter subjetivo, se mantienen normalmente implícitos y en general condicionan las decisiones pedagógico-didácticas en relación con la selección y organización de saberes y contenidos a enseñar. Este proceso de selección de contenidos, denominado por de Alba (1998) proceso de desarrollo curricular, comienza cuando los sujetos del desarrollo curricular, esto es, el profesorado, convierten un currículo prescripto, en la práctica, reinterpretándolo y transformándolo según sus propios proyectos sociales. De acuerdo con Bordoli (2006a, 2006b), el currículum, como producto cultural, supone el reconocimiento de los "saberes legítimos” y éstos vehiculizan la operación de la transposición didáctica. Las distintas alternativas se sintetizan en el currículum real (1991). Frigerio, Poggi, Tiramonti y Aguerrondo (1992) expresan, reconociendo la gran capacidad docente en la utilización de su saber experto y la puesta en práctica de lo curricular que: "Un buen currículum puede perder sus "bondades" si los actores no se apropian de él, y a su vez un currículum obsoleto, es "moldeado" de tal modo que sus límites son compensados por la acción de los docentes” (p. 71).

Las finalidades de la educación científica que sustenta el profesorado (Furió et al, 2001; Banet, 2007) y las intencionalidades curriculares (Gallego, 2004) que proponen las y los docentes, se configuran, en general, a partir de los objetivos educativos dentro del proyecto social y de la concepción de ciencia que quieren enseñar. Como se planteó anteriormente, desde el campo de la investigación didáctica actual, la alfabetización científica de la ciudadanía es considerada la gran finalidad de la enseñanza de las ciencias. Entonces cabe preguntarse: ¿Cuáles son las finalidades de la enseñanza de la Física según los profesores en el nivel en el que se desarrollan? Se trata de explicitar cómo el profesorado concibe a la 
Física como disciplina educativa y abordar las tensiones que surjan con relación al conocimiento elaborado desde la investigación didáctica y las demandas de las políticas educativas.

Por otra parte, alfabetización científica no representa un concepto unívoco, de modo que es necesario explicitar un recorte u opción conceptual al referirse a la misma. Así mismo, diversos autores asimilan el término a otros como: alfabetización tecnológica, cultura científica, comprensión pública de la ciencia, educación CTS (Ciencia, Tecnología y Sociedad), educación para todos o competencia científica. Sintetizando la idea anterior, Gómez-Martínez, Pessoa y Sasseron (2015) plantean que, aun cuando el disenso prima sobre el consenso respecto a la definición y alcance de la alfabetización científica, son múltiples los equipos de investigación que refieren a la importancia de esta como objetivo y/o parámetro de la educación científica. Siendo entonces relevante qué y en qué contexto los docentes elaboran conceptualmente respecto a la misma.

En el apartado siguiente se presentan aspectos metodológicos y de análisis que permitieron elaborar algunas reflexiones, conclusiones y muchas otras interrogantes para seguir estudiando, en función de las interfases planteadas: alfabetización científica, finalidades de enseñanza, concepciones docentes, currículo.

\section{Marco metodológico}

La metodología elegida en ambas investigaciones ha sido fundamentalmente cualitativa ya que se busca conocer, describir y comprender aspectos del pensamiento del profesorado que lo lleva a establecer ciertas decisiones en relación con las acciones de su quehacer docente. Taylor y Bogdan (1986) consideran que la metodología cualitativa produce datos descriptivos emanados desde las propias personas a través de sus palabras y de sus conductas observables. Los problemas de investigación se abordan como estudio de caso. Interesa por tanto conocer, lo que dice y hace la profesora o el profesor respecto a los asuntos de interés mencionados, en forma directa o mediante conexiones que evidencien relaciones (elaboraciones meta-científicas del profesorado). Los estudios llevados adelante tienen como referente a analizar aspectos del discurso del profesorado contextualizados en sus prácticas de enseñanza de la Física. Al respecto Mosquera (2008) dice:

A partir de la comprensión de las actividades que los profesores programan, organizan, ejecutan en el aula de clase, es posible identificar concepciones, ideas, creencias y juicios de valor que sobre la ciencia asume el profesor, así como también es posible identificar sus concepciones, creencias y valores acerca de la investigación científica, de las relaciones entre la investigación científica y la investigación en el aula de clase como medio para el aprendizaje de las ciencias, del papel de la historia de las ciencias en la enseñanza de las ciencias, etc. (Mosquera, 2008, p. 109)

Para la etapa de indagación preliminar (de ambas investigaciones), se confeccionó un formulario semiestructurado ${ }^{1}$ en forma colaborativa entre las autoras, puesto que existen múltiples aspectos en común en los estudios desarrollados y se entendió que el diseño en conjunto redundaría en riqueza para las investigaciones, al tiempo que el número de respuestas y el compromiso de quienes responden sería mayor si se les hacía llegar un cuestionario y no dos. Sobre los hallazgos e 
interpretación de las respuestas dadas por el profesorado al mismo es que se desarrolla en este artículo. Este cuestionario, en formato formulario buscó obtener: a) datos contextuales de los y las docentes: edad, años de trabajo, cursos a cargo, titulación, efectivización, cursos de actualización y perfeccionamiento docente y b) información relativa a las concepciones y la práctica docente, que incluyó aspectos como: los grupos de estudiantes (grado, orientación y opción) en que trabajó en el último año lectivo, cuáles recursos y estrategias didácticas utilizó, qué selección y organización de los contenidos y saberes a enseñar eligió diseñar, opiniones sobre finalidades de la enseñanza de Física en bachillerato e identificación de indicadores de alfabetización científica, entre otros. El diseño del cuestionario pretendió abarcar diferentes posibilidades de respuesta para el encuestado. El tipo de preguntas planteadas fue variado, desde elegir entre dos o más opciones, ordenar según escala de prioridades, valorar enunciados, responder con textos breves, hasta desarrollar una idea personal para argumentar. De aquí el considerarlo semiestructurado.

Se envió el formulario por correo electrónico, de manera individual, a un conjunto de 120 docentes de todo el país. Esta cifra estuvo en el entorno del $10 \%$ de profesores en condición de enseñantes de cursos de Física en Uruguay. La elección no aleatoria de docentes invitados a contestar el cuestionario, se fundamenta en dos aspectos: a) son profesionales de la educación que comparten intereses comunes y específicos, concurren a congresos, salas, encuentros vinculadas con la enseñanza de Física; b) el cuestionario es una herramienta que permite acotar el campo de investigación, contribuye y da insumos para comparar las respuestas a nivel nacional dado que la distribución territorial de los contactados corresponde a múltiples lugares del país.

\section{Resultados y análisis}

De los 120 cuestionarios enviados se obtuvieron 63 respuestas. En un sentido general, se puede inferir que la muestra de docentes que aportó insumos a través del cuestionario conforma un cuerpo de profesores con trayectorias profesionales afianzadas, mayoritariamente dedicados a la enseñanza en bachillerato. A continuación, la Tabla 1 resume algunas de las mismas.

Tabla 1. Resumen de las características contextuales del profesorado encuestado

\begin{tabular}{|c|c|c|c|c|c|}
\hline \multirow{3}{*}{ Rango de edades (en años) } & \multicolumn{5}{|c|}{ Número de profesores/as } \\
\hline & $20-30$ & $31-40$ & $41-50$ & $51-60$ & +60 \\
\hline & 4 & 19 & 22 & 17 & 1 \\
\hline \multirow{2}{*}{ Años de trabajo en CES } & $1-10$ & $11-20$ & $21-30$ & +30 & \\
\hline & 10 & 22 & 22 & 9 & \\
\hline \multirow{2}{*}{ Ciclos plan 2006 en que trabajan } & \multicolumn{2}{|c|}{$1^{\circ}$ y $2^{\circ}$} & \multicolumn{3}{|c|}{ Sólo $2^{\circ}$} \\
\hline & \multicolumn{2}{|c|}{10} & \multicolumn{3}{|c|}{49} \\
\hline \multirow{2}{*}{ Formación y carrera docente } & \multicolumn{2}{|c|}{ Egresados } & \multicolumn{3}{|c|}{ Efectivos } \\
\hline & \multicolumn{2}{|c|}{59} & \multicolumn{3}{|c|}{57} \\
\hline
\end{tabular}

Elaboración: Araújo (2018).

Fuente: Cuestionario. 


\subsection{Finalidades educativas del bachillerato}

La opinión del profesorado de Física sobre este aspecto se vincula con la misión fundacional de la Enseñanza Secundaria del Uruguay, caracterizada principalmente por la preparación para el ingreso a las carreras universitarias (Figura 1). La persistencia de estas ideas se evidenció en muchas de las respuestas del profesorado cuando se les preguntó acerca de dichas finalidades. Un 54\% manifestó como prioritaria la finalidad propedéutica del bachillerato, mientras que igual porcentaje de docentes (41\%) consideraron como segunda prioridad las opciones, terminal y la habilitación para el mundo del trabajo. Puede decirse que coexisten varias concepciones acerca de dichas finalidades, puesto que las diferencias obtenidas a partir de la aplicación del cuestionario no son significativas.

Figura 1: Gráfico de análisis de respuestas a la pregunta 12.

Pregunta: Ordena según tus prioridades las opciones que plantean finalidades educativas del Bachillerato de Educación Secundaria.

(Considera el 1 como más prioritario y el 4 como menos prioritario)

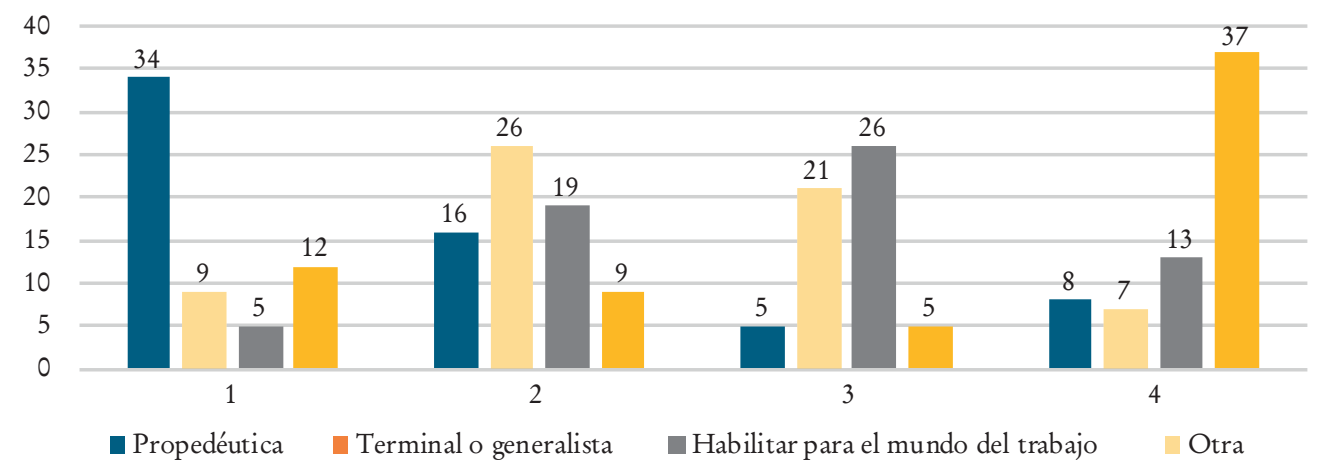

Elaboración: propia.

Fuente: Cuestionario.

\subsection{Finalidades de la enseñanza de la Física}

Cuando se les preguntó a los y las docentes sobre las prioridades que dan a la enseñanza de Física en Bachillerato, una gran mayoría optó por considerar la promoción de habilidades cognitivas en los estudiantes como lo más importante (63\%), y, en igual porcentaje (35\%), le siguieron las opciones de habilitar para continuar estudios superiores y favorecer una mejor comprensión de las leyes de la naturaleza. La finalidad de alfabetizar científicamente fue valorada como principal prioridad por el $41 \%$ de las y los docentes (Figura 2).

La mayoría de las respuestas dadas por el profesorado consideró que la función principal del bachillerato es continuar estudios superiores pero la finalidad más importante que atribuyen a la enseñanza de Física es facilitar el desarrollo cognitivo en los estudiantes. Es posible deducir del análisis de las respuestas que los profesores consideran que un prerrequisito fundamental para continuar estudios superiores sea la promoción de habilidades cognitivas. 
Figura 2: Gráfica de análisis de respuestas a la pregunta 13.

Pregunta: Ordena según tus prioridades las opciones que plantean finalidades de la enseñanza de Física en bachillerato. (Considera el 1 como más prioritario y el 5 como menos prioritario)

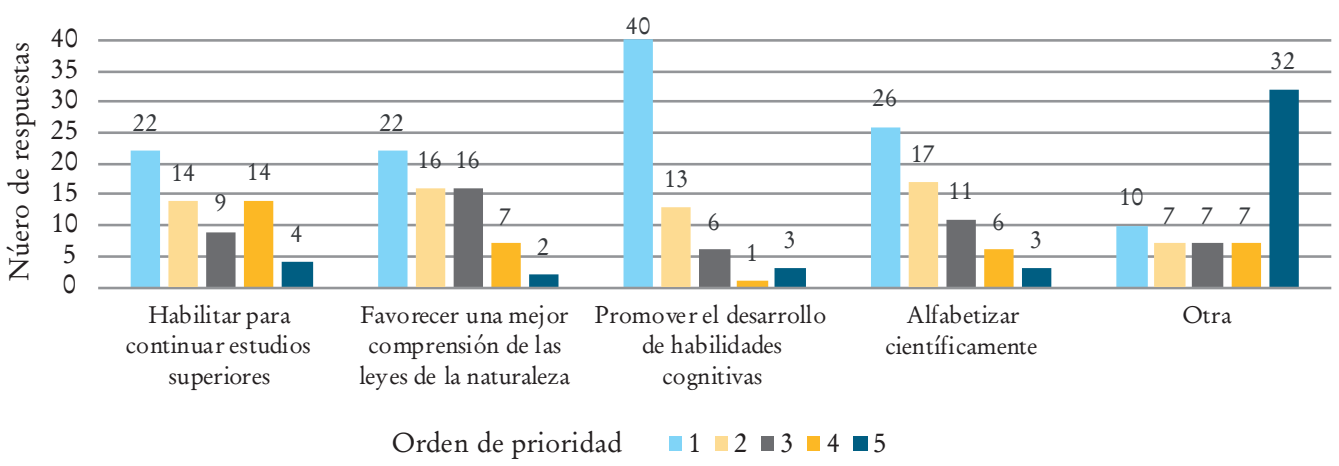

Elaboración: propia.

Fuente: Cuestionario.

\subsection{Lectura de las fundamentaciones programáticas}

Al ser consultados respecto a si leen habitualmente la fundamentación de los programas de la asignatura del nivel o niveles en que se desempeñan, la respuesta fue marcadamente afirmativa, tal como se aprecia en la Figura 3, y, entre las razones que señalaron para respaldar esta acción se encuentra especialmente el carácter orientador de los diseños programáticos para la planificación de las prácticas. Sin embargo, varias respuestas refirieron a la atención dada a la fundamentación para conocer y posicionarse desde otras miradas, discutiendo, problematizando y complementando las propuestas programáticas.

\subsection{Indicadores de alfabetización científica en los programas}

Una notable mayoría del profesorado reconoce en las propuestas programáticas asuntos que identifican con la alfabetización científica, tal como se ilustra el la Figura 4. Un aporte significativo de observación contextual (de quienes investigan), es que sólo en el programa de primer año de Bachillerato aparece una referencia explícita al decir "alfabetizarse científicamente". Por lo cual se deduce que, varias de las asociaciones que el profesorado ha realizado refieren a cuestiones implícitas de los discursos (ya que no todos se desempeñan en el nivel de primer año de Bachillerato) y por tanto amplía la presencia del concepto en los documentos, desde su perspectiva. Podría inferirse entonces, que gran parte del profesorado planifica su enseñanza sobre una concepción de alfabetización científica o se preocupa por ello. 
Figura 3: Atención prestada por el profesorado a los documentos programáticos para los distintos cursos de Física. (Pregunta 9)

Pregunta: ¿Le es habitualmente la fundamentación y orientaciones que forman parte de la propuesta programática oficial para los distintos cursos de Física en Secundaria?

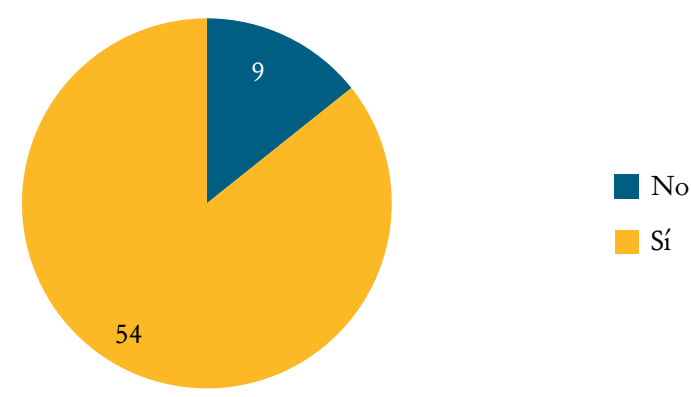

Elaboración: propia.

Fuente: Cuestionario.

Figura 4: Reconocimiento de indicadores de alfabetización científica en las propuestas programáticas de Física. (Pregunta 11)

Pregunta: La alfabetización científica como enunciado explícito o concepto implícito, ¿forma parte de alguna/s de las propuestas programáticas para los cursos de Física de Secundaria

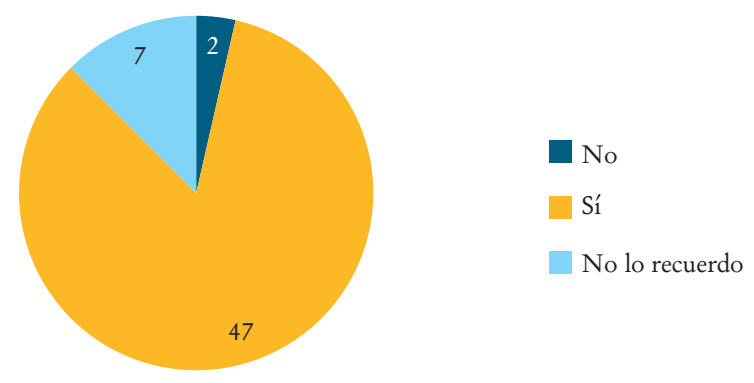

Elaboración: propia.

Fuente: Cuestionario.

\subsection{Planificación e implementación de los cursos}

En relación con los propósitos deseados al momento de diseñar e implementar las actividades de enseñanza, las respuestas destacaron como más importante la realización de aquellas que estimulen la motivación de los estudiantes (87\%), seguido por la opción de actividades que vinculen los contenidos físicos con el contexto de los estudiantes (78\%). En tercer lugar, se situó la promoción de problemas con abordaje intra, inter o multidisciplinar (63\%) y en el último lugar el desarrollo de todos los contenidos conceptuales prescriptos en el programa oficial (52\%), asuntos que se presentan en la Figura 5. 
Figura 5: El profesorado manifiesta sus prioridades al momento de planificar sus clases de Física. (Pregunta 14)

Pregunta: Al momento de planificar e implementar el o los cursos, ordena según tus prioridades los siguientes aspectos que se mencionan. (Considera el 1 como más prioritario y el 4 como menos prioritario)

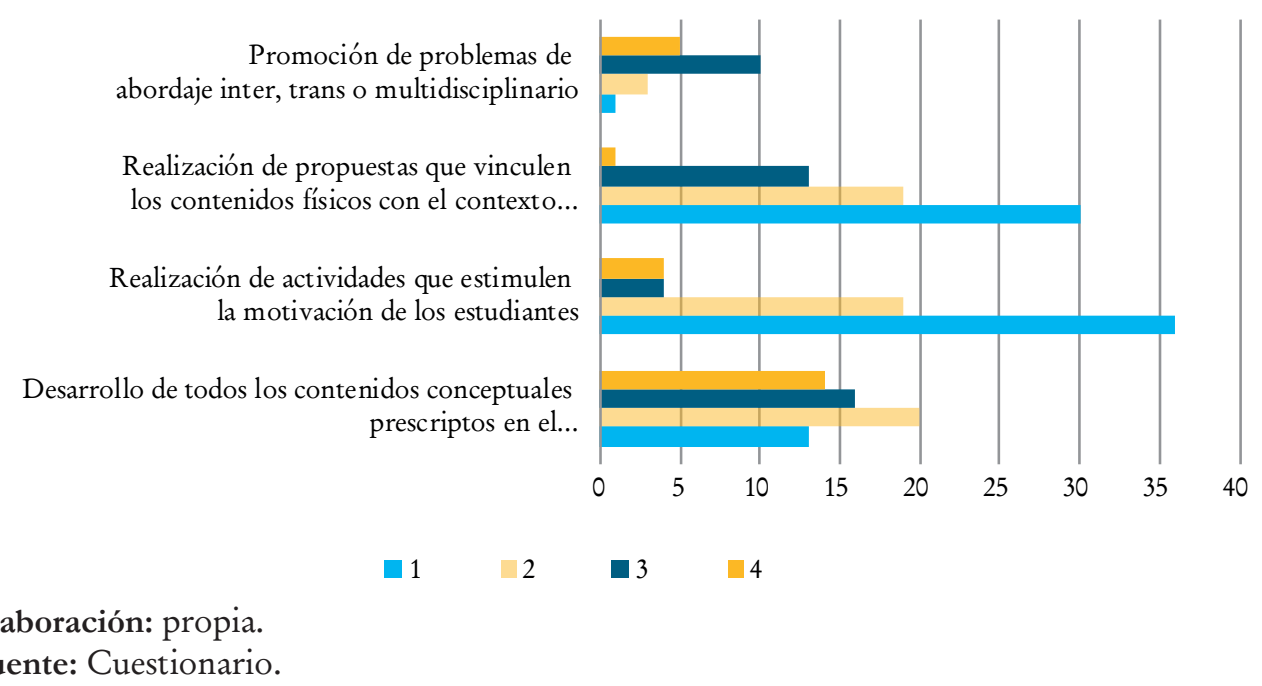

\subsection{Selección y organización de contenidos}

Los y las docentes argumentaron que la selección y organización de contenidos de enseñanza para sus cursos de Física la realizan fundamentalmente en concordancia con su propia experiencia, con lo establecido en los programas oficiales, en función de los intereses del grupo-clase y de la opinión de otros colegas, de acuerdo con lo que se muestra en la Figura 6.

\subsection{Estrategias, actividades y recursos de enseñanza}

Entendidas estas como las herramientas con que el profesorado cuenta al momento de enseñar. Las respuestas dadas en el formulario, que se visualizan y organizan en la Figura 7, mostraron que las estrategias más utilizadas por los docentes de Física en sus clases son: la resolución de problemas de lápiz y papel (94\%) y la realización de trabajos prácticos o experimentos (89\%). En menor porcentaje aparecen las estrategias vinculadas al uso de las tecnologías de la información y la comunicación -TICs- (56\%) y en similares frecuencias en sus usos los enfoques basados en el error en la enseñanza y el abordaje desde la historia y la filosofía de las ciencias (32\% y 33\% respectivamente). Finalmente, se valoran las estrategias a partir de controversias tecnocientíficas que pueden implicar juego de roles, debates, paneles, etc. (10\%). 
Figura 6: Gráfico de análisis de la respuesta 16 del cuestionario. Resumen de las cuatro opciones más elegidas.

Pregunta: La selección y organización de contenidos lo realizas fundamentalmente en concordancia con:

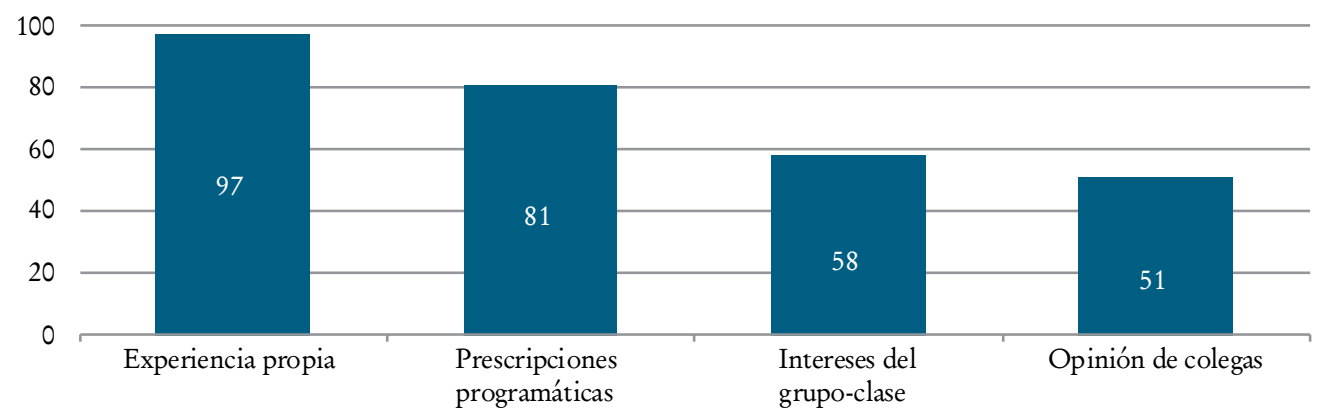

Elaboración: propia.

Fuente: Cuestionario.

Figura 7: El profesorado manifiesta la frecuencia con que las estrategias o enfoques de enseñanza puestos a consideración por las investigadoras fundamenta su práctica docente. (Pregunta 17)

Pregunta: ¿En qué "medida" los siguientes enfoques (estrategias) de enseñanza fundamentan tus clases de Física?

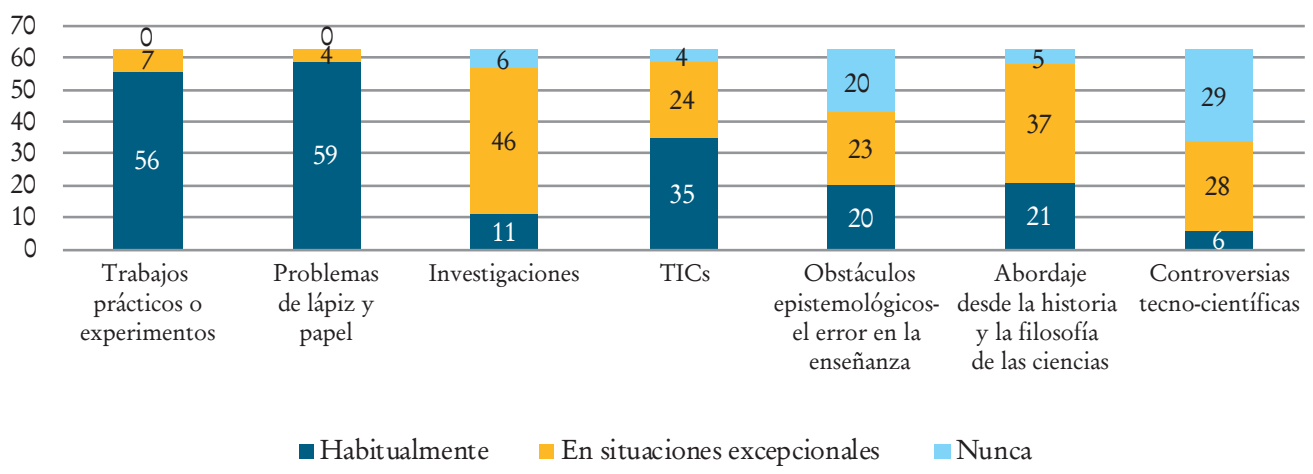

Elaboración: propia.

Fuente: Cuestionario.

A continuación, se realiza una observación y análisis pormenorizado de los insumos surgidos en las respuestas a la consigna 17 del cuestionario, anteriormente ilustrados en la Figura 7.

\subsubsection{Abordaje bistórico-epistemológico}

El 33\% del profesorado consultado dijo utilizar este enfoque. En general las ciencias han sido enseñadas como un saber inalterable, acabado y acumulativo, donde los conceptos constituyen la razón de ser del conocimiento, lo que ha conducido a reproducir definiciones, leyes y teorías. La transmisión de "saberes cerrados" en sí mismos, para su reproducción, es contraria no sólo al proce- 
so histórico de producción de esos conocimientos, (ya que genera una visión deformada y estática de su construcción), sino también a los mecanismos de aprendizaje. Actualmente, tanto la epistemología como la historia de la ciencia (entre otros) son reconocidas por las investigaciones en el área de la didáctica y los académicos, como aportes constitutivos de lo que han llamado Naturaleza de la Ciencia $(\mathrm{NdC})$, considerada esta como abordaje y enfoque fundamental para promover la alfabetización científica de los estudiantes.

\subsubsection{El error en la enseñanza}

Este concepto tiene su origen en la noción de obstáculo epistemológico propuesto por Bachellard (1938) citado por Astolfi (2001) en la que el conocimiento científico sólo se establece en ruptura con la "experiencia primera" y el "pensamiento común”. Esto se vincula con el conocimiento previo que los estudiantes traen y que son modificados (o no) en el proceso de enseñanza. El 32\% de los y las docentes manifestó utilizarla.

\subsubsection{Controversias tecnocientíficas}

Sólo el 10\% del profesorado dijo utilizarlas. Esta técnica de abordaje de situaciones problema, es ampliamente considerada dentro del enfoque CTSA, afiliado directamente a la promoción de la alfabetización científica. Los estudiantes se aproximan a los problemas científicos y a las posibles soluciones de estos utilizando juegos de roles, debates, la confrontación argumentada, partiendo de asumirse cada uno como actor, con un rol o papel definido, interesado en defender su punto de vista en dicha controversia. Los alumnos preparan su argumentación e intercambian opiniones defendiendo sus posturas, construyendo así soluciones y transitando por procesos de aprendizaje en contexto, ligados en general a lo que ocurre en las comunidades de proximidad, en la sociedad. En esta línea de acciones educativas, Martín y Osorio (2003, p. 177) expresan que "una verdadera educación democrática deberá hacer del aula un verdadero laboratorio, un simulador de la participación democrática”, y por tanto de construcción de ciudadanía.

\subsubsection{Problemas de lápiz y papel}

En el detalle representado en la Figura 8, se observa que casi tres cuartas partes del conjunto de docentes, propone situaciones de análisis cerradas, de única respuesta, es decir sin grados de libertad; estas están determinadas desde el momento de presentar la consigna y las condiciones de las cuales se parte. Eventualmente puede haber recorridos alternativos en la búsqueda de la respuesta. Los ejercicios, a su vez, resultan de una aplicación directa de una o varias ecuaciones y se sustentan en la repetición. Ni con problemas cerrados ni con ejercicios, el alumno tiene la posibilidad de preguntarse, generar hipótesis, etc. El profesor pregunta y el alumno responde, cuando puede. Los problemas abiertos o investigaciones, en cambio, le proporcionan autonomía al alumno para ensayar 
diversos recorridos, lo desafían y lo motivan. Como puede apreciarse, solamente un muy pequeño porcentaje, cercano al $2 \%$, propone problemas a modo de pequeñas investigaciones.

Figura 8: Preferencias del profesorado para los dseños de problemas de lápiz y papel. (Pregunta 19)

Pregunta: Respecto a los problemas de lápiz y papel, entiendes que las propuestas que trabajas con tus estudiantes son mayormente:

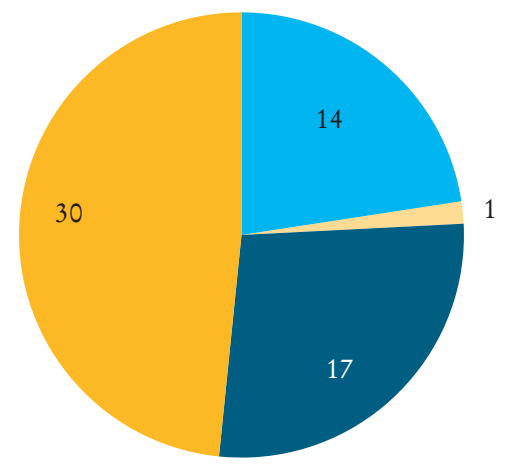

Ejercicios

Problemas a modo de pequeñas investigaciones

Problemas abiertos

Problemas cerrados

Elaboración: propia.

Fuente: Cuestionario.

\subsubsection{Las actividades experimentales}

Las respuestas (Figura 9) mostraron que el 44\% son diseñadas para contrastar teorías, el 37 \% para deducir o "descubrir” aspectos relacionados con las teorías, el $16 \%$ se orientan a modo de pequeñas investigaciones y sólo el $3 \%$ realiza actividades demostrativas (o de cátedra). Si bien se aprecia el apartamiento del enfoque tradicional de enseñanza, con sólo $3 \%$ de docentes que mayormente proponen actividades demostrativas, a la vez, la inmensa mayoría señala su preferencia respecto a diseños de trabajos prácticos donde el estudiante tiene muy poca autonomía. Su rol principalmente es de ejecutor, seguir las pautas dadas por el docente para observar ("descubrir" o comprobar) algún fenómeno físico y estudiar algunas relaciones entre variables.

Hoy en día, desde las investigaciones y construcciones conceptuales en el campo de la didáctica de la ciencia, se entiende que tanto problemas de lápiz y papel como trabajos prácticos, remiten al mismo objeto cognitivo, la configuración de un problema (Sanmartí y Márquez, 2012; Couso, Izquierdo y Merino, 2008). Y se insiste que para construirse debe haber una pregunta de inicio. Dice Sanmartí en Ballesta (2018), si no hay pregunta, no hay problema; y en lo posible que la pregunta la formule el propio estudiante. Una pregunta investigable, un problema auténtico, que conecte con el contexto del estudiante, que le otorgue autonomía, tanto del profesor/a como de los materiales didácticos (Pessoa de Carvalho, 1998). De modo que, en este aspecto, existe desencuentro entre los datos interpretados del campo y los soportes teóricos que se constituyeron como categorías conceptuales para el análisis. Desencuentro en el sentido de no coincidencia de significados. 
Figura 9: Preferencias del profesorado sobre la orientación para los trabajos prácticos o actividades experimentales. (Pregunta 18).

Pregunta: Las actividades experimentales que realizas son mayoritariamente para:

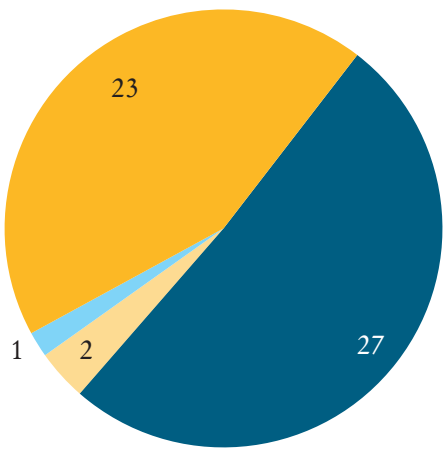

Comprobar o verificar asuntos de la teoría

Demostrativas (docente ejecuta)

Investigaciones/pequeñas investigaciones

Deducir o "descubrir" asuntos de la teoría

Elaboración: propia.

Fuente: Cuestionario.

\section{Discusión y conclusiones}

Todas las respuestas dadas por los sujetos estuvieron atravesadas por sus creencias, ideologías, posicionamientos políticos, convicciones personales. Tal como lo expresan los autores referentes, el pensamiento del profesorado es la voz interior que se expresa, fundamentando opiniones y acciones de los sujetos investigados.

Se puede apreciar que el profesorado de Física está capacitado para desempeñar su rol y se preocupa por su profesionalismo. Conoce las fundamentaciones e intenciones curriculares/programáticas y se apropia de ellas con diversas posturas; desde considerarlas orientadoras hasta críticas de oposición. Si bien reconocen la presencia de la alfabetización científica en los documentos programáticos curriculares, de modo explícito o implícito, en las prácticas de enseñanza (según sus propias manifestaciones) no hay acciones tendientes a su promoción.

Las opiniones se posicionaron en un espacio en el que se cruzaron concepciones sobre qué y para qué enseñar Física. La finalidad de desarrollar habilidades cognitivas a través de la enseñanza de Física recogió el mayor porcentaje de respuestas. Sin embargo, esta aspiración se pone en tensión respecto de cómo se proponen lograrlo, ya que las estrategias y actividades más utilizadas (resolución de problemas de lápiz y papel y actividades experimentales) no plantean desafíos cognitivos superadores de la mera repetición o reproducción.

Otro aspecto jerarquizado sobre las finalidades de la enseñanza de Física fue la de acercar los conocimientos físicos a la vida cotidiana de los estudiantes. Este consenso da cuenta de la necesidad de abordar la enseñanza de los saberes y conocimientos científicos contextualizados al entorno, al mundo en el que habitan los estudiantes, pero, las prácticas educativas no se condicen con ello. De la mano de esto, atender a las relaciones CTSA, el trabajo inter, trans, multi disciplinar, los debates o controversias tecnocientíficas no son, en general, considerados por el profesorado. 
Las intencionalidades curriculares que los sujetos investigados manifestaron proponerse en los procesos de desarrollo curricular que realizan, se entrecruzan con las finalidades de la enseñanza que ellos mismos conciben. En ese sentido se podrían diferenciar intencionalidades vinculadas con los intereses específicos de las orientaciones y opciones que cursan los estudiantes, con lo que los y las docentes consideran prerrequisitos para estudios superiores y con aspectos formativos más generales en el marco de la alfabetización científica.

\section{Reflexiones finales}

Las demandas de nuevas políticas públicas educativas estuvieron entre las respuestas del profesorado al preguntarles qué consideraban necesario hacer para la mejora de la enseñanza de la Física. Son múltiples los planteos que realizaron (Figura 10), desde cambios en la organización y gestión institucional, en planes y programas adecuándose a los nuevos perfiles de estudiantes, a sus intereses, en el reglamento de evaluación y pasaje de grado, hasta mejoramiento del salario, forma de distribución y elección de cargos y horas, pasando por profundizar en inversión económica para equipar laboratorios.

Figura 10: Respuestas más representativas a la pregunta 21 del cuestionario: ¿Qué consideras que debería hacerse a nivel de políticas educativas públicas para mejorar la enseñanza de la Física en Uruguay?

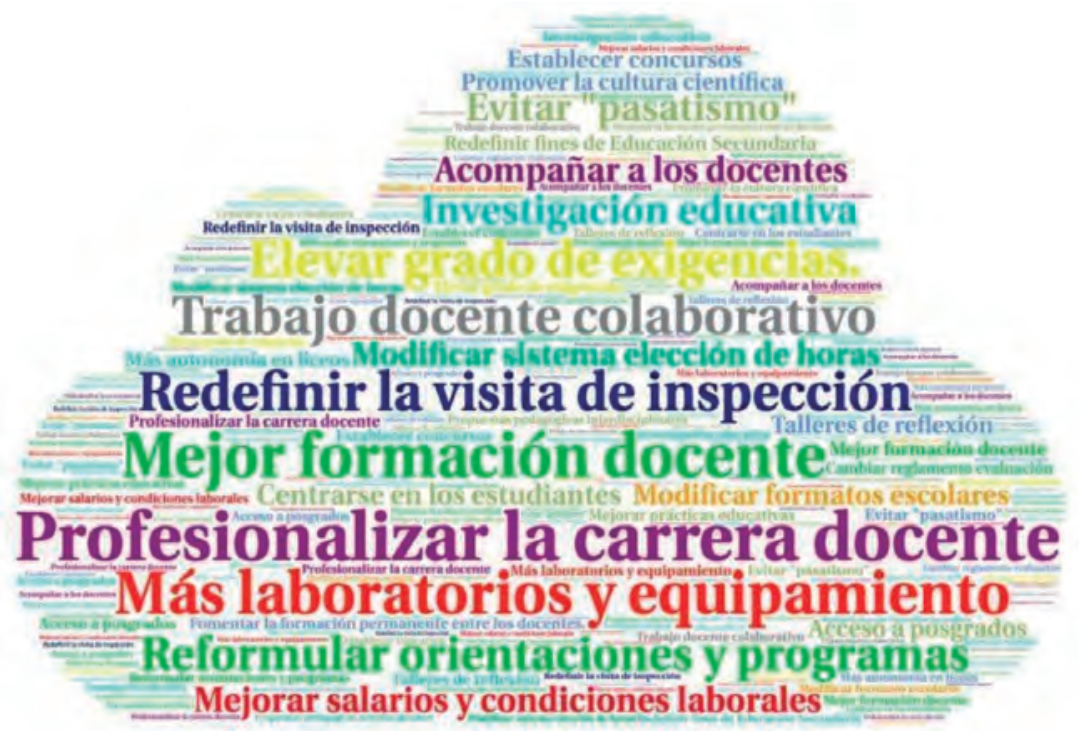

Elaboración: Araújo (2018).

Fuente: cuestionario

Algunas respuestas hicieron especial énfasis en cambios en la metodología de enseñanza, promoviendo estrategias que sean de interés de los estudiantes. Otras en cambio, se orientaron en favor de aumentar la exigencia, de "no bajar el nivel" (Figura 11).

El colectivo docente destacó especialmente la necesidad de formación permanente a través del acceso a cursos de posgrado y profesionalización en servicio. El intercambio entre colegas, el trabajo compartido que permita la reflexión 
colectiva, fueron aspectos que el profesorado jerarquizó como forma de mejorar la enseñanza y facilitar el aprendizaje de Física. El compromiso con su profesión y con el estudiantado fue un aspecto que surgió a partir de las respuestas, evidenciando, por una parte, una autocrítica sincera y rigurosa, y, por otra parte, definiendo responsabilidades atribuibles al sistema educativo.

Figura 11: Respuestas más significativas a la pregunta 22: ¿Qué consideras que podrías hacer tú para mejorar la enseñanza de la Física en Uruguay?

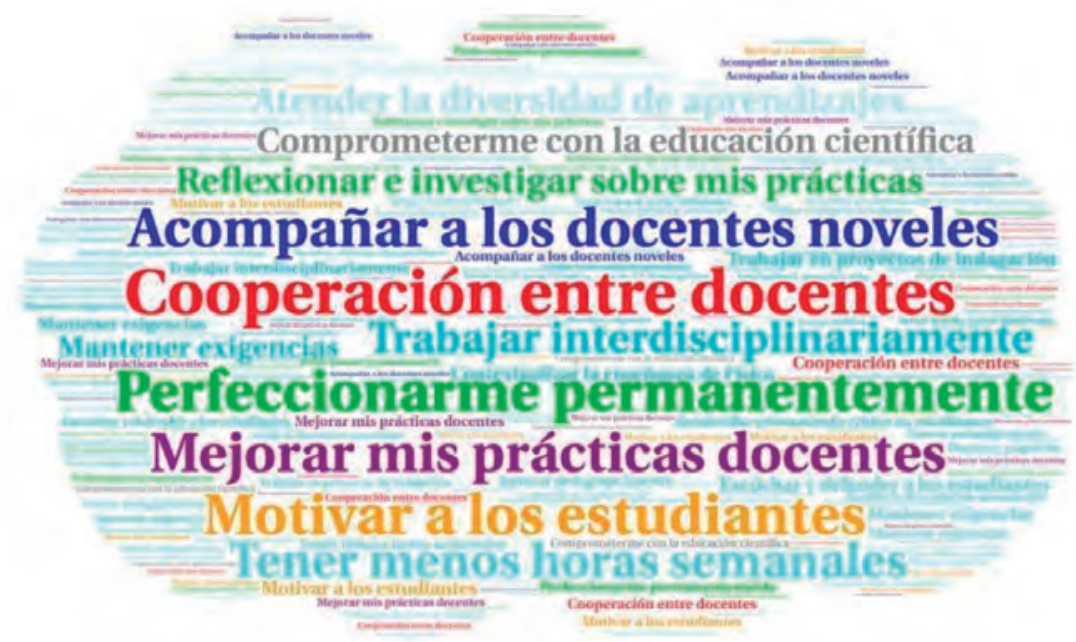

Elaboración: Araújo (2018).

Fuente: cuestionario

En este marco vuelve a ponerse en cuestión, cuáles son verdaderamente las finalidades de la enseñanza secundaria. El sistema educativo se ve interpelado para que defina claramente cuál es la misión y establezca nuevos rumbos. 


\section{Referencias}

Acevedo, J. (2004). Reflexiones sobre las finalidades de las ciencias: educación científica para la ciudadanía. Revista Eureka sobre Enseñanza y Divulgación de las Ciencias, 1(1), 3-16. Recuperado de http://www.redalyc.org/articulo. $\mathrm{oa} ? \mathrm{id}=92010102$

ANEP. (2014). Acciones educativas en Ciencia y Tecnología en ámbitos de educación formal y no formal- Primer informe. Uruguay. Recuperado de http://www.anep.edu.uy/ sites/default/files/images/Archivos/publicaciones direcciones/DSPE/ pisa/pisa2015/Publicaciones/Libro acciones educativas.pdf

Araújo, C. (2018). Currículo y Enseñanza. Concepciones y prácticas docentes en la enseñanza de Física del bachillerato uruguayo actual: un estudio a partir de docentes del departamento de Colonia. Tesis de Maestria, FLACSO, Montevideo.

Astolfi, J. (2001). Conceptos clave en la didáctica de las disciplinas. Sevilla: Diada Editorial.

Ballesta, M. (2018). Alfabetización científica desde la perspectiva de las y los docentes de Física en Uruguay. Un estudio en Primer Año de Bachillerato de Enseñanza Secundaria. Tesis de Maestría, FLACSO, Montevideo.

Banet, E. (2007). Finalidades de la educación científica en secundaria:opinión del profesorado sobre la situación actual. Enseñanza de las Ciencias, 25 (1), 5-20. Recuperado de http://ddd.uab.es/pub/edlc/02124521v25n1p5.pdf

Bordoli, E. (2006). La dialéctica del saber en el marco del currículo. Apuntes para pensar la igualdad. Ponencia. Instituto de altos estudios- Centro de estudios multidisciplinarios, Montevideo.

Bordoli, E. (2006, b). ¿Qué se pone en juego en una reforma curricular? Implicancias y limitaciones de la misma (2a. parte). Revista Quehacer educativo, (77), 17-23.

Couso, D., Izquierdo, M., \& Merino, C. (2008). La resolución de problemas. En A. Gómez, C. Merino, \& A. Adúriz-Bravo, Áreas y Estrategias de Investigación en la Didáctica de las Ciencias Experimentales. Colección Formación en Investigación para Profesores (Vol. 1). Balleterra Universitat Autònoma de Barcelona.

De Alba, A. (1998). Currículum: Crisis, Mito y Perspectivas. Argentina: Miño y Dávila Editores.

Díaz, C, Martínez, P, Roa, I, \& Sanhueza, M. (2010). Los docentes en la sociedad actual: sus creencias y cogniciones pedagógicas respecto al proceso didáctico. POLIS, Revista Latinoamericana, 25 (9), 421-436. Recuperado de http://www.redalyc.org/comocitar.oa?id=30512376025

Frigerio, G, Poggi, M, Tiramonti, G, \& Agerrondo, I. (1992). Las instituciones educativas: Cara y ceca. Elementos para su gestión. Buenos Aires: Editorial Troquel.

Frigerio, G. (1991). Currículum presente, ciencia ausente. Normas, teorías y críticas. Buenos Aires: Editorial Troquel.

Furió, C, Vilches, A, Guisasola, J, \& Romo, V. (2001). Finalidades de la enseñanza de las ciencias en la secundaria obligatoria. ¿Alfabetización científica o preparación propedéutica? Enseñanza de las Ciencias, 19 (3), 365-376. Recuperado de https://ddd.uab.cat/pub/edlc/02124521v19n3/02124521v19n3p365.pdf 
Gallego, R. (2004). Un concepto epistemológico de modelo para la didáctica de las ciencias experimentales. Revista Electrónica de Enseñanza de las Ciencias, 3 (3),301-319. Recuperado de http://reec.uvigo.es/volumenes/volumen3/ REEC $3 \quad 3 \quad 4 . p d f$

Gil, D, Macedo, B, Martínez, J, Sifredo, C, Valdés, P, \& Vilches, A. (2005). ¿Cómo promover el interés por la cultura científica? Santiago de Chile: OREALC/ UNESCO. Recuperado de http://unesdoc.unesco.org/ images/0013/001390/139003S.pdf

Lemke, J. (2006). Investigar para el futuro de la educación científica: nuevas formas de aprender, nuevas formas de vivir. Enseñanza de las Ciencias, 21 (1), 5-12. Recuperado de www.raco.cat/index.php/Ensenanza/article/ download/73528/84736

Martin, M, \& Osorio, L. (2003). Educar para participar en ciencia y tecnología. Un proyecto para la difusión de la cultura científica. (OEI, Ed.) Revista Iberoamericana de Educación, 32, 165-210.

Meinardi, E. (. (2010). Educar en ciencias. Buenos Aires: Paidós.

Mosquera, C. (2008). El cambio en la epistemología y en la práctica docente de profesores universitarios de Química. Tesis doctoral, Departament de Didáctica de les Ciencies Experimentals i Socials. Universitat de València. Recuperado de http:// www.tdx.cat/bitstream/handle/10803/9644/mosquera.pdf?sequence $=1$

Pessoa de Carvalho, A. (1998). Ciências no ensino fundamental. O conbecimiento físico. Sao Paulo: Editora Scipione.

Pozo, J, Sheuer, N, Pérez, M, Mateos, M, Martín, E, \& de la Cruz, M. (2006). Nuevas formas de pensar la enseñanza y el aprendizaje. las concepciones de profesores y alumnos. Barcelona: Editorial Graó.

Revetria, J. (2014). Alfabetización cientifica: participación de los docentes a través de sus formas de enseñanza. Tesis de Maestría, Instituto universitario Claeh, Montevideo.

Sanmartí, N, \& Márquez, C. (2012). Enseñar a plantear preguntas investigables. En: Hacia la competencia científica. Alambique Didáctica de las Ciencias Experimentales, 70, 27-36.

Sanmartí, N. (20 de abril de 2018). (M. Ballesta, Entrevistador) Montevideo.

Sasseron, L. (2011). Alfabetizaçãon cintífica e documentos oficiais brasileiros: um diálogo na estructuração do ensino da Física. En Ensino de Física. Sao Paulo: Cengage Learning Ediçoes Ltda.

UNESCO. (1999). Conferencia Mundial sobre la Ciencia para el siglo XXI: Un nuevo compromiso. Budapest. Recuperado de http://www.unesco.org/ science/wcs/esp/declaracion_s.htm

Valdivia, N. (2016). Alfabetización científica en Física. El cambio curricular no ha sido suficiente. Praxis Pedagógica, 16 (18), 71-87. Recuperado de http:// dx.doi.org/10.26620/uniminuto.praxis.16.18.2016.71-87

Vildósola, X. (2009). Las actitudes de profesores y estudiantes, y la influencia de factores de aula en la transmisión de la naturaleza de la ciencia en la enseñanza secundaria. Tesis doctoral, Departament de Didàctica de la Matemàtica i de les Ciències Experimentales, Universidad de Barcelona. Recuperado de http://diposit. ub.edu/dspace/handle/2445/41440 


\title{
Anexos
}

Anexo 1. Presentación y preguntas del cuestionario en línea.

\section{Reflexiones sobre la enseñanza de la Física}

\author{
Estimados colegas:
}

Quienes elaboramos esta herramienta de indagación, somos las Profesoras de Fisica Cristina Araújo y Marcela Ballesta, en el marco de la Maestria Sociedad, Educación y Política de FLACSO Uruguay en convenio con el CFE.

El objetivo principal del instrumento que les acercamos es recoger información acerca de los procesos/trayectos de formación de los profesores de Fisica de Uruguay y otros relativos a sus prácticas de aula e institucionales asi como de expectativas, demandas y necesidades para la mejora de su labor docente. A partir del análisis de los mismos intentaremos elaborar reflexivamente respecto a nuestras tesis de investigación, no sólo para obtener el título de posgrado para el que estamos cursando sino y más importante aún, generar algún tipo de conocimiento que aporte a nuestro colectivo docente y a nuestro sistema educativo todo.

Los minutos que ustedes destinen a responder estas cuestiones serán muy valorados por nosotras y los convertirán en parte del proceso. Estimamos que necesitarán 20 minutos para completar el formulario ( 24 consignas entre obligatorias y no obligatorias). Todas las respuestas son relevantes, las que se darán con si/no, con la elección de una o varias categorias, con un desarrollo de ideas más o menos extenso, etc. Lo más importante y que damos por descontado, al tiempo que agradecemos, es la honestidad intelectual de cada uno y su compromiso.

\begin{abstract}
Garantizamos absoluta reserva en el manejo de la información obtenida y aseguramos que en los informes que se escribirán no aparecerán nombres ni referencias directas a personas o instituciones que permitan identificarlas. También nos comprometemos a compartir, con aquellos que manifiesten interés, los hallazgos de nuestras investigaciones una vez defendidas nuestras tesis.
\end{abstract}

Esperamos sus elaboraciones hasta el 22/12/2017.

Desde ya muchas gracias

Cristina y Marcela

\section{Procesos de formación docente}

1. Edad *

\section{1. ¿Eres EGRESADO/A de algún Instituto de Formación Docente como Profesorla de} Fisica?

Marca solo un ovaio.

$$
\begin{aligned}
& \text { Sí } \\
& \text { No }
\end{aligned}
$$

\section{2. ¿Eres efectivo/a como Profesor/a de Física en el Consejo de Educación Secundaria} (CES)?*

Marca solo un óvalo.

\section{$\mathrm{Si}$}


4. 3. ¿Cuántos años hace que trabajas en el CES como docente de Física?*

5. 4. ¿Has realizado OTRAS carreras de formación de grado y/o post grado? (Aquí Física refiere a la disciplina y a su enseñanza)

Marca solo un óvalo por fila.

\begin{tabular}{|c|c|c|c|c|}
\hline & Finalizada & $\begin{array}{l}\text { En } \\
\text { curso }\end{array}$ & $\begin{array}{c}\text { En suspenso o } \\
\text { abandonada }\end{array}$ & $\begin{array}{c}\text { Finalizada/s una/s } \\
\text { y en curso otra }\end{array}$ \\
\hline $\begin{array}{l}\text { De grado vinculado } \\
\text { con Física } \\
\text { De grado no vinculad } \\
\text { con Física }\end{array}$ & & & & \\
\hline $\begin{array}{l}\text { De post grado } \\
\text { vinculado con Fisica }\end{array}$ & & & & \\
\hline $\begin{array}{l}\text { De post grado no } \\
\text { vinculado con Fisica }\end{array}$ & & & & \\
\hline
\end{tabular}

6. 5. Considerando los últimos DOS años, indica sỉ has participado, ya sea como expositor/a o asistente de (marca todas las opciones que corresponda): *

Selecciona todos los que correspondan.

Congresos organizados por APFU

Congresos de Enseñanza de la Fisica (o las Ciencias, en Uruguay o exterior)

Cursos de verano organizados en la órbita del CFE relacionados con la Física

Cursos, seminarios, talleres relacionados con Fisica, con evaluación

Cursos, seminarios, talleres, charlas relacionados con Fisica, sin evaluación

Otros espacios de formación en ciencias

Otros espacio de formación permanente (no considerado en los anteriores)

Ninguna actividad de formación

\section{La práctica docente}

7. 6. Considerando sólo instituciones en la órbita del CES, durante 2017, te desempeñas como docente de Fisica en qué plan, nivelles y orientación/es de BACHILLERATO? * Selecciona todos los que correspondan.

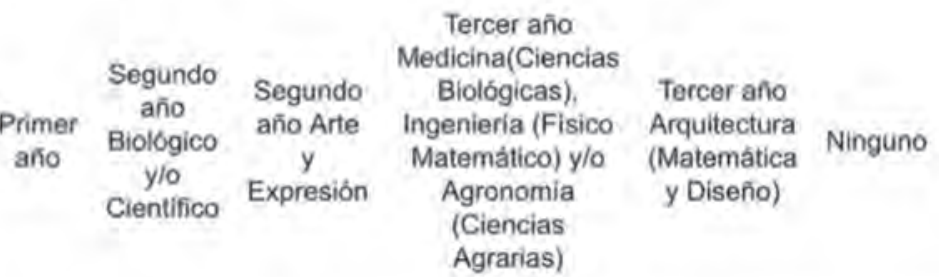

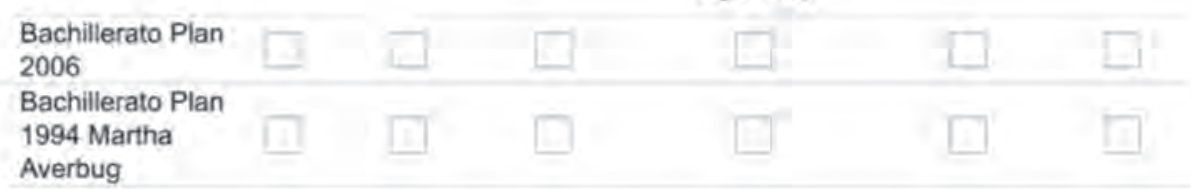


8. 7. Considerando sólo instituciones en la órbita del CES, durante 2017, te desempeñas como docente de Física (o Ciencias Físicas) en qué plan o programa y nivel/es de PRIMER CICLO? *

Selecciona todos los que correspondan.

$\begin{gathered}\text { Primer } \\ \text { año }\end{gathered}$
$\begin{aligned} & \text { Plan 2006 año } \\ & \text { Plan 1996 EE }\end{aligned}$
Plan 2009-2012-
2013
Otros programas

9. 8. En què curso/s te has desempeñado con más frecuencia en los últimos cuatro años?. Por qué?

10. 9. Lees habitualmente la fundamentación y orientaciones que forman parte de la propuesta programática oficial para los distintos cursos de Física en Secundaria? * Marca solo un óvalo.

$$
\begin{aligned}
& \text { Sì } \\
& \text { No }
\end{aligned}
$$

11. 10. Referido a tu respuesta anterior, ¿por qué?

12. 11. La alfabetización cientifica como enunciado explícito o concepto implicito, forma parte de alguna/s de las propuestas programáticas para los cursos de Fisica de Secundaria?"

Marca solo un óvala.

$$
\begin{aligned}
& \text { Si } \\
& \text { No } \\
& \text { No lo recuerdo }
\end{aligned}
$$

13. 12. Ordena según tus prioridades las opciones que plantean finalidades educativas del Bachillerato de Educación Secundaria *

(Considera el 1 como más prioritario y el 4 como menos prioritario) Marca solo un óvalo por fila.

Propedéutica
Terminal o generalista
Habilitar para el munda del trabajo
Otra


14. 13. Ordena según tus prioridades las opciones que plantean finalidades de la enseñanza de Fisica en bachillerato. *

(Considera el 1 como más prioritario y el 5 como menos prioritario)

Marca solo un óvalo por fila.

\section{$\begin{array}{lllll}1 & 2 & 3 & 4 & 5\end{array}$}

Habilitar para continuar estudios superiores

Favorecer una mejor comprensión de las leyes de la naturaleza

Promover el desarrollo de habilidades cognitivas

Alfabetizar cientificamente

Otra

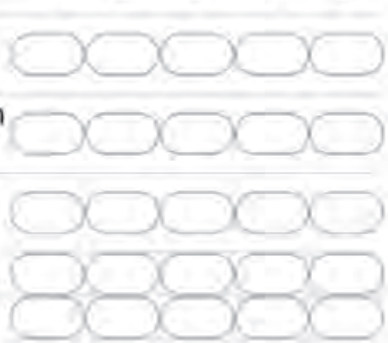

15. 14. Al momento de planificar e implementar el o los cursos, ordena según tus prioridades los siguientes aspectos que se mencionan: ${ }^{\star}$

(Considera el 1 como más prioritario y el 4 como menos prioritario)

Marca solo un óvalo por fila.

\section{$\begin{array}{llll}1 & 2 & 3 & 4\end{array}$}

Desarrollo de todos los contenidos conceptuales prescriptos en el programa oficial

Realización de actividades que estimulen la motivación de los estudiantes

Realización de propuestas que vinculen los contenidos fisicos con el contexto de los estudiantes Promoción de problemas de abordaje inter, trans o multidisciplinario

16. 15. Ordena según tus prioridades, las siguientes fuentes o recursos para preparar tus clases: *

(Considera el 1 como más priontario y el 6 como menos prioritario)

Marca solo un óvalo por fila.

Libros especificos de fisica de nivel superior

Textos recomendados a tus

estudiantes

Materiales de elaboración propia

Sitios de internet

Materiales elaborados par

colectivos docentes

Otros
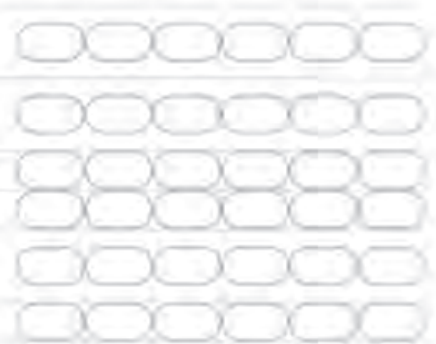
17. 16. La selección y organización de los contenidos de enseñanza las realizas fundamentalmente en concordancia con (selecciona hasta cuatro): "

Selecciona todos los que correspondan.

la experiencia propia

la lógica disciplinar que aparece en los libros especificos de la asignatura

núcleos o temas-problemas con caracteristicas interdisciplinares

las caracteristicas e intereses del grupo-clase

la opinión de colegas

lo establecido en los programas oficiales

los lineamientos de las politicas publicas educativas

los proyectos de centro

otros

18. 17. En qué "medida" los siguientes enfoques (estrategias) de enseńanza fundamentan tus clases de Física? *

Marca solo un óvalo por fila.

Trabajos prácticos o
experimentos
Problemas de lápiz y papel
Investigaciones
TICs (simuladores, laboratorios
remotos, interfaces y
sensores,etc.)
Obstáculos epistemológicos- el
error en la enseñanza
Abordaje desde la Historia y
Filosofia de las ciencias
Controversias tecno-cientificas
(juego de roles, debates sobre
problemáticas de relevancia
social, o similares)

19. 18. Las actividades experimentales que realizas son mayoritariamente: *

Marca solo un óvalo.

Demostrativas (ei profesor ejecuta)

Para comprobar o verificar asuntos de la teoría

Para deducir o "descubrir" asuntos de la teoria

Investigaciones/ Pequeñas investigaciones

20. 19. Respecto a los problemas de lápiz y papel, entiendes que las propuestas que trabajas con tus estudiantes son mayormente?: *

Marca solo un óvalo.

\section{Ejercicios}

Problemas cerrados

Problemas abiertos

Problemas a modo de pequeñas investigaciones 
21. 20. Recomiendas libro/s a tus estudiantes para acompañar el curso?. Por qué? (en caso afirmativo cuál/es para cada nivel). ${ }^{*}$

22. 21. Qué consideras que deberia hacerse a nivel de políticas educativas pủblicas para

mejorar la enseñanza de la Fisica en

Uruguay?

\section{Cierre}

Llegaste al final del formulariol Esperamos que el recorrido haya sído reflexivo a la vez que dinámico. Una vez más agradecemos tu colaboración.

Cristina y Marcela

24. Cualquier otro asunto que quieras agregar, comentar o sugerir será bienvenidol.... 